\title{
Controversies in acute multiligamentary knee injuries (MLKI)
}

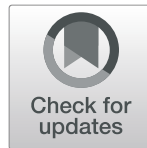

Manuel F. Mosquera ${ }^{1,2^{*}}$ D, Alejandro Jaramillo ${ }^{3}$, Ricardo Gil ${ }^{1}$ and Yessica Gonzalez ${ }^{1}$

\begin{abstract}
Summary: Multiligament injuries of the knee (MLKI), remain an infrequent pathology especially in developed countries compared to mono-ligament lesions. In Colombia, MLKI is frequent due to the high accident rate on motorcycles. In the city of Bogota alone, about 160 motorcycle accidents have been estimated daily, being one of the cities that proportionately use this means of transport less compared to small cities. The term MLKI, include all ruptures of two or more major ligaments and therefore it has a broad spectrum of clinical presentation which creates a great challenge for the orthopedists and the surgeons envolved in this topic. The literature is rich in studies level IV but very poor in level I and level II, which generates controversies and little consensus in the diagnosis and treatment of this pathology. However there has been a gradual and better understanding of all factors involved in the treatment of MLKI that has improved the functional results of these knees in our patients, in fact we currently are more precise to achieve accurate diagnosis, evolved from not surgical approach to operate most, applying new anatomical and biomechanical concepts, with specialized and skill surgical techniques with more stable and biocompatible fixation implants, which allow in most cases to initiate an early integral rehabilitation program. Nevertheless due to the complexity and severity of the lesions, in some patients the functional results are poor. The goal of this revision is to identify the most frequent controversies in the diagnosis and treatment of MLKI, defining which of them are agreed according to what is reported in the literature and share some concepts based from the experience of more than 25 years of the senior author (MM) in the management of these injuries.
\end{abstract}

Level of Evidence: $\vee$ - Expert Opinion.

Keywords: Multi-ligamentary knee injuries, Knee dislocation, Multi-ligament knee surgery

\section{Introduction}

Multi-ligament knee injuries (MLKI) have been defined as those that are accompanied by rupture of two or more of the four major ligaments, referring to the cruciate ligaments and collaterals, although some identify six [63]. Schenck et al. [96, 97, 117] classified the knee dislocations in five degrees according to the injured ligaments and not by the direction of displacement as it was traditionally done, because most of the dislocations came reduced into the emergency room and were unclassificable [118]. The number of ligaments involved, which of them are injured and the associated injuries is closely related

\footnotetext{
* Correspondence: mosco61@gmail.com

${ }^{1}$ Clinica Erasmo, Valledupar, Colombia

${ }^{2}$ Clinica La Carolina, Carrera 14 \# 127-11 Cons 307-308, Bogota, Colombia

Full list of author information is available at the end of the article
}

to the magnitude of the trauma and the mechanism of production of the lesion [34]. In general, high-energy trauma usually injure three or the four major ligaments and those of low energy up to two ligaments, usually one cruciate and one collateral [102], but in some special conditions such as morbid obesity, ultra-low-energy trauma [5, 33] causes severe injuries that it can include the four major ligaments. Although the MLKI is of rare presentation in many countries [3, 11, 25, 59] in Colombia is a frequent pathology in the emergency services due to the high rate of accidents that occur in motorcycles, especially in small cities.

The majority of MLKI are product of a knee dislocation, (Fig. 1a knee dislocation KDIV), (Fig. 1b, Knee dislocation KDV) and the importance of suspect and diagnose it, is related by the high degree of association 


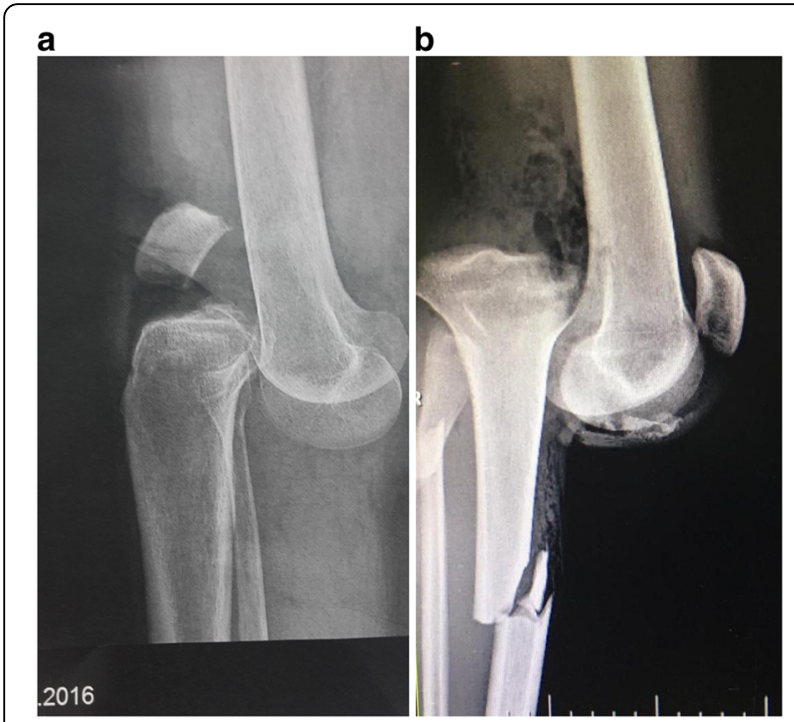

Fig. 1 a knee dislocation KDIV. b Knee dislocation KDV

of lesion of the popliteal artery, which varies according to the series between 10 to $65 \%[16,37,73,110]$. Even when we diagnose a knee dislocation, a neuro-vascular lesion may go unnoticed if the patient is not properly examined and if some simple tests such as the AnkleBrachial index that can alert us to a popliteal arterial lesion are not used $[25,73,119]$ On some occasions when patients arrive unconscious in the emergency department, a peroneal nerve lesion may be neglected which can have serious consequences [35, 58, 82].

\section{Controversies in diagnosis and treatment}

Given the hetereogenicity of multi-ligament injuries of the knee, its broad spectrum of clinical presentation and the poor level I-II evidence reported in the literature regarding all aspects of treatment, there are many controversies that have not been agreed upon by the experts [19], for this reason, this review intends to give to the reader some treatment guidelines in such controversial aspects, supported by the evidence that exist and for the authors experience mainly by the senior (MM), who has dedicated more than 25 years of his professional career in dealing with this pathology.

To start with, the only "consensus" that currently exists in the treatment of MLKI in Schenck KDII / III / IV lesions, is that operated patients have a better outcome than those treated without surgery $[20,52,54,90,93]$ in terms of stability, work return and quality of life. Although there are reports of patients operated by MLKI who have returned to their same sporting level $[56,104]$ it is usual for their level of return to work and sport to be very low $[24,40]$ therefore these injuries can never be compared with isolated lesions of the cruciates or grade KDI of the Schenck classification in terms of their clinical results. It is not clear in the literature what it means have a "good result" in multi-ligament surgery, however it is generally accepted that the goals are to achieve a "stable" and functional joint, even though a considerable number of patients in their evaluations and arthrometric test, have residual laxity which is often not symptomatic.

Except in unconscious patients, in the authors article experience, the clinical examination of the knee to establish which ligaments are compromised, is painful which obliges the surgeon to diagnose injuries by inspection and palpation of the knee and for the use of tests that mobilize the knee in short arcs of flexion, such as the traditional and inverted lachman test, the recurvatum and external rotation test, the dial test, (Fig. 2 Dial Test at $30^{\circ}$ ) and the lateral and medial opening in flexion and extension. With these tests and with the help of magnetic resonance imaging (MRI), $100 \%$ certainty of which major ligaments are compromised can be reached.

The First controversy that arises is to know what the ideal test is if there is a high suspicion of vascular injury after having performed the ankle-brachial index [67]. There is no agreement in the literature if the arteriography is superior to angio-tac (CTA) or angioresonance, but taking into account the sensitivity, specificity, non-invasiveness, lower morbidity and the better availability of CTA in the emergency department, it is preferred, to make a surgical decision of exploration and revascularization $[10,88]$. In these cases, the use of an external fixator after the procedure is mandatory and non-controversial [72]. In the authors article opinion, given that the vascular lesion in the multi-ligament injuries that come from a knee dislocation are high [74], even with a normal pedal pulse, it is mandatory in all patients to perform the ankle-brachial index to rule out injuries that due to their characteristics may go unnoticed

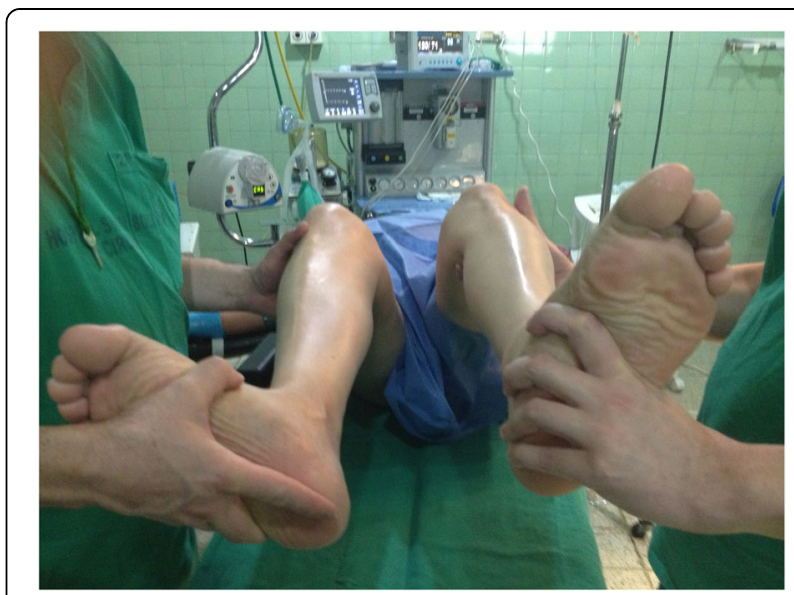

Fig. 2 Dial Test at $30^{\circ}$ 
with catastrophic consequences. Therefore, Mills et al. [76] in a prospective study found that in all patients in whom the index was below 0.90 , there was an arterial lesion that required repair / grafting. Anyway, if the index is not conclusive or is doubtful, is mandatory to make a CTA or Arteriography. We have keep in mind that certain vessels lesions, tear only the intimate layer making the diagnosis even more difficult and reconstruct this knees could have catastrophic consequences.

The Second controversy refers to the appropriate treatment of the peroneal nerve lesions, which can occur between $5 \%$ and $40 \%$ in a knee dislocation [42, 82] where in some special conditions such as in the obese patients, the risk may be greater [89]. There is no level I-II evidence, if acute exploration is necessary or conversely, the evolution should be follow up with clinical and electrophysiology control. Wodmass et al. [122] in a systematic review reported that only $40 \%$ of patients who have complete lesions recover active ankle dorsiflexion and $87 \%$ when the lesions are partial. In an article published by Samson et al. [95], they recommend in their treatment algorithm in continuous nerve lesions, early neurolysis with weekly and electrophysiological clinical control, and re-exploration if there is no progression in the improvement of symptoms and electromyographic findings. In complete lesions without tissue loss, these should be repaired early and augmented with grafts usually taken from the Sural Nerve, but in severe lesions with tissue loss the best option that is showing better results are nerve transfers [36, 121] Garozzo et al. $[30,31]$ and Ferrasi [27] have reported excellent results of peroneal nerve injuries performing early exploration, repair and nerve grafting, as well as transfer of the posterior tibial tendon. In the authors article opinion, clinical injury of the peroneal nerve is one of the indications for early surgery, ideally before two weeks and this should always be accompanied by the hand of a surgeon expert in peripheral nerve injuries (Fig. 3. Peroneal Contusion. Courtesy of Ricardo Garcia MD). The delay in the treatment of these lesions generate poor functional results even in knees that have achieved good joint stability [123].

The Third controversy refers about the type of ideal pre-operative and post-operative immobilization for those knees with KDIII / IV lesions. In this topic, there is no level I evidence that recommends some type of immobilization over another, but in general it is preferred that in lesions of the four major ligaments with knees that displace after reduced, grossly unstable, and post repair or reconstruction of the ligaments, the hinged external fixator is better than the rigid one, (Fig. 4. Rigid external fixator) because it has the advantage of stabilizing and allowing early mobility, reducing the risk of arthrofibrosis, characteristic of these extensive

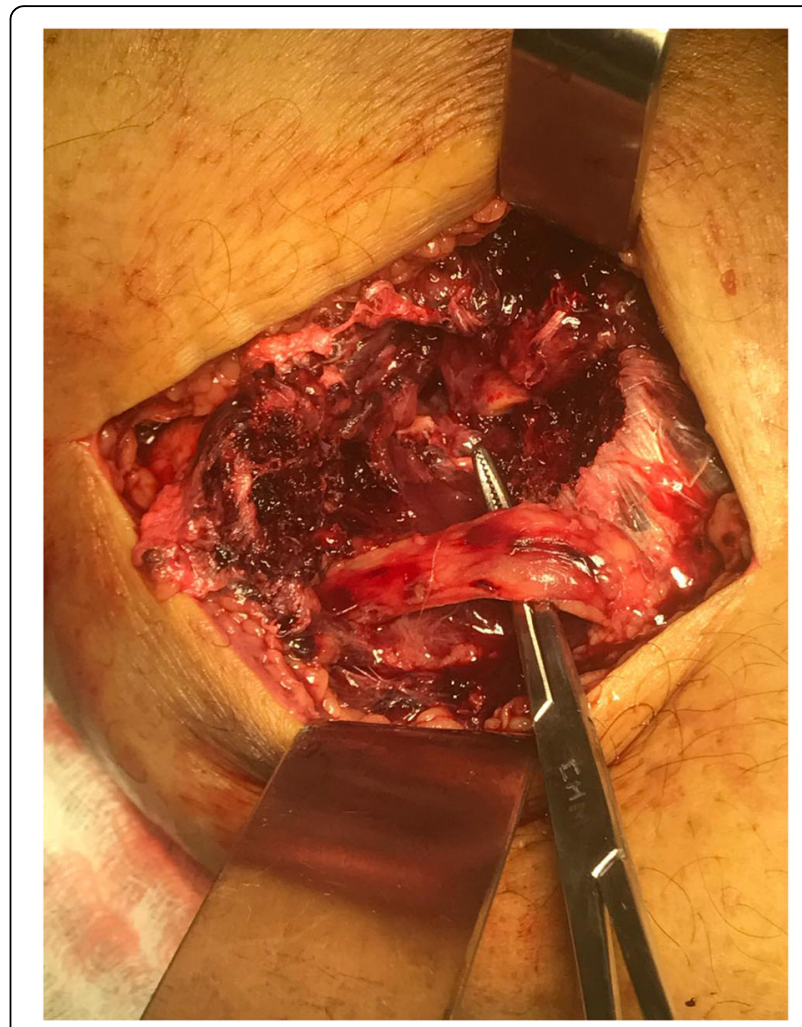

Fig. 3 Peroneal Contusion. Courtesy of Ricardo Garcia MD

soft tissue injuries [107]. In addition, some authors such as Lucidi [68], Marcacci [70], Zaffagnini [125], and Angellini [1], recommend it after surgery to protect the ligament reconstruction with good results, especially when posterior cruciate ligament surgery has been performed. Stannard et al. [106] in a prospective randomized study of 77 patients with severe instability found that in patients who had an hinged external fixator placed, ligament reconstruction failed significantly less than those who had a traditional brace. In the authors article opinion, whenever the use of an external fixator is required, whether due to vascular repair, open dislocation or severe instability, the hinged fixator should be preferred because it reduces the risk of arthrofibrosis in these patients, which it has a worse prognosis than residual instability, nevertheless if for any reason was chosen a rigid fixator, it is advisable to remove it between 3 to 4 weeks, recover knee motion and then do the ligament surgery.

The Fourth controversy refers to the ideal time "timing" to operate these patients, and whether it is better to do it in a single or in two stage. Levi et al. [64], in a systematic review and Harner et al. [38] found that early surgery before 3 weeks produces better results in terms of stability, function, return to work and sport than late surgery. Shelbourne et al. [101], Rihn [94], Owens [87] also advocate early surgery before 3 weeks for the 


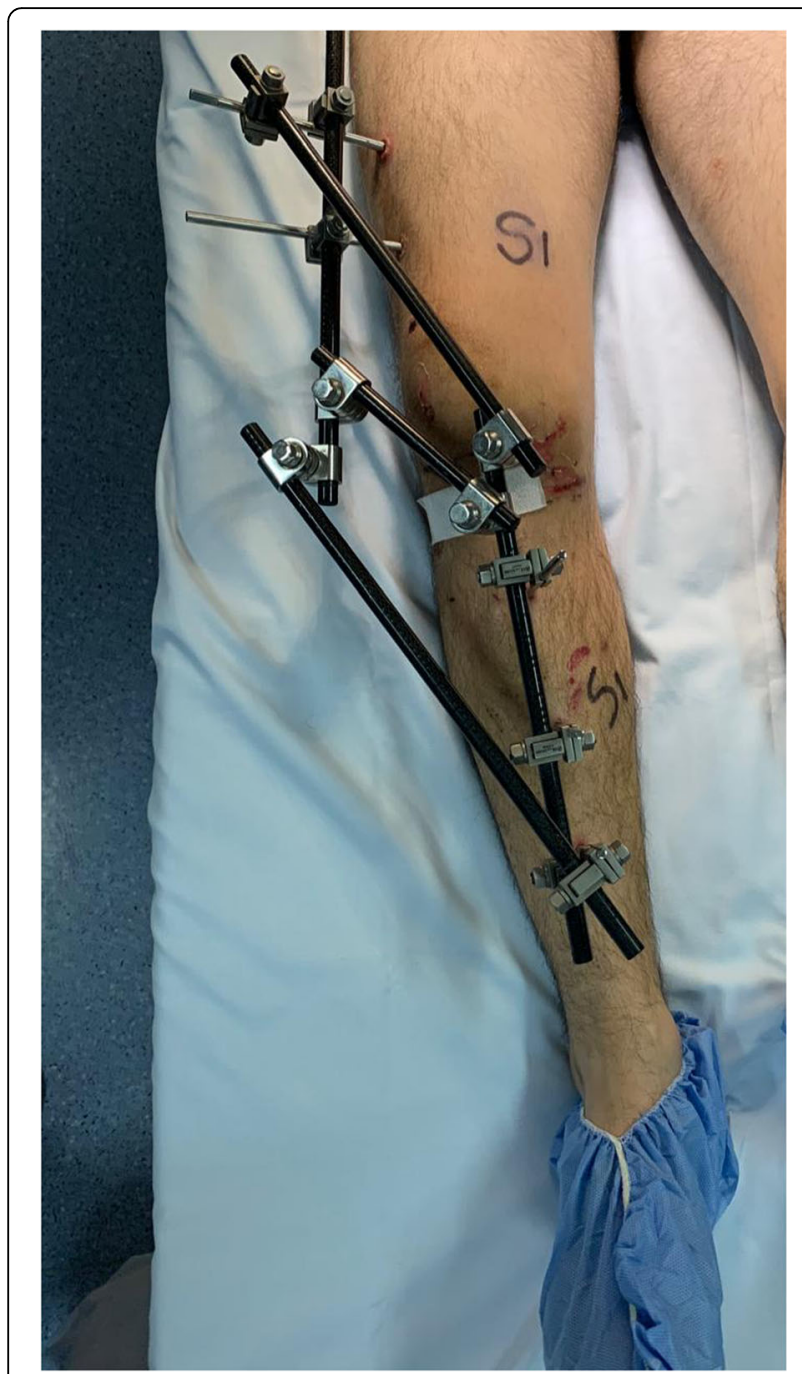

Fig. 4 Rigid external fixator difficulty of collateral exploration after this time and the inability to repair them. Vicenti et al. [116] in another systematic review find that it is better to intervene patients before 3 weeks because it produces better results on functional scales. However, other authors prefer surgery in two stages $[8,86,109]$. Mook et al. [79] in a systematic review found similar results in terms of stability and function by performing late or two-stage surgery with similar complications, compared to early surgery. Jiang et al. [47] in another systematic review reported better results in terms of stability in $\mathrm{KD} / \mathrm{III}$ lesions with two-stage surgery. La Prade et al. [60] in a level IV study in 194 patients reported good results according to the Tegner, Lysholm and Womac scales, with surgery in a single surgical stage performed in acute or chronic phase. The definition in the literature of what it is acute or chronic is confusing and what it is early surgery and late surgery in terms of weeks. In some studies the early one is defined as interventions in the first week, others before the third week, as well occur as in the late surgery that in some cases is define it at 4 weeks and in others at 6 weeks. In general, the authors of this article recommend use the terms of immediate surgery the one that is performed in the first $24 \mathrm{~h}$ usually due to vascular repair and open knee dislocation, early surgery that is performed before 3 weeks, and late surgery after 4 to 6 weeks. In this regard, early surgery is recommend it in cases of fixation of bone fracture (KDV), frank lesion of the peroneal nerve, and in the desinsertions / avulsions of the corners and cruciates (Fig. 5a. MCL desinsertion) (Fig. 5b. PCL avulsion). Always the repair procedure should starts with the corners, which include no just ligaments but perypherical meniscus and capsular tissue, to improve knee stability (Fig. 6. Open Medial Meniscus Repair). Once the tissues are closed, we repair cruciates and add some stitchs to the meniscus to strength the repair (Fig. 7a. In-out meniscal repair). On the last 5 years,
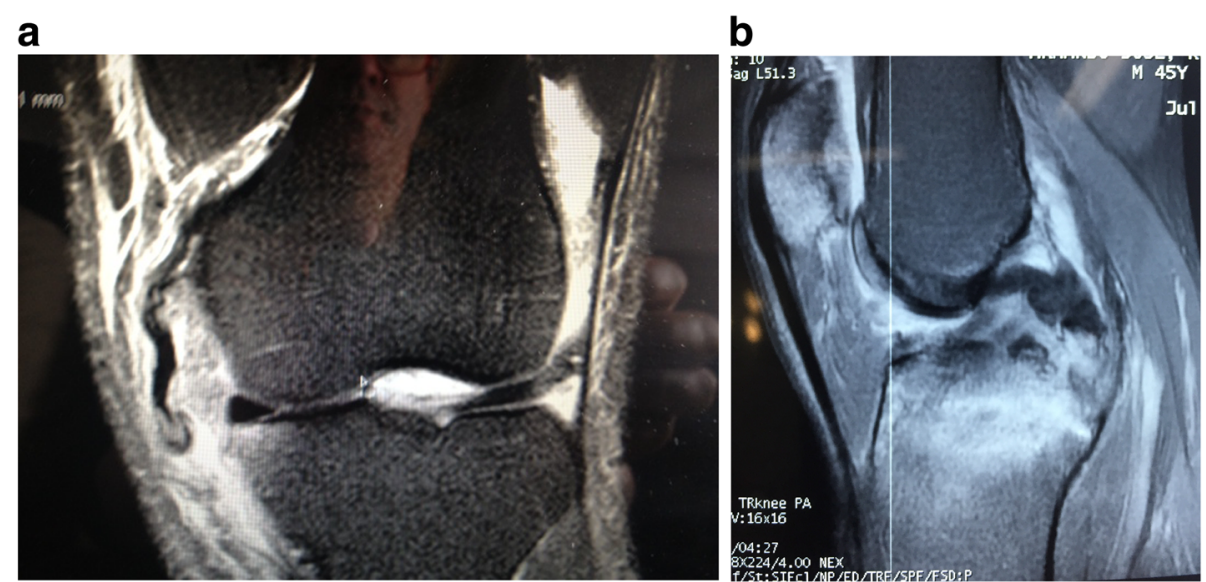

Fig. 5 a $M C L$ desinsertion. b PCL avulsion 


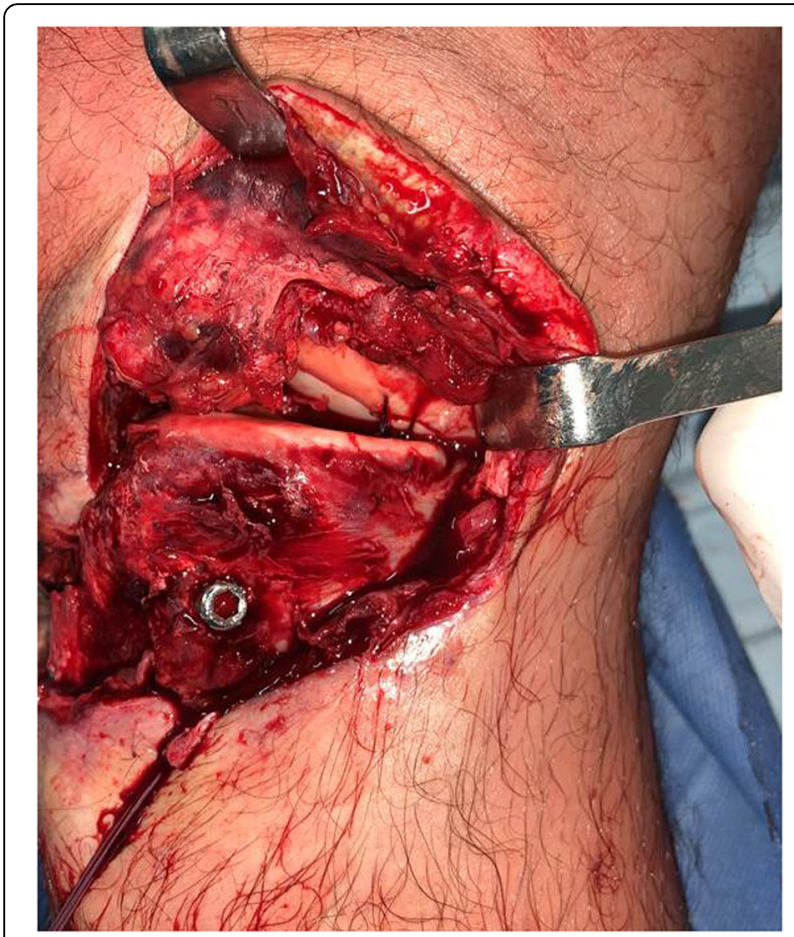

Fig. 6 Open Medial Meniscus Repair

we've repaired all cruciates remnant with high strength sutures and using in some cases augmentation with tapes (Fig. 7b. ACL Repair and Internal Brace). In this situation, it is imperative to continuously check the pressure of the compartments even if they are closed and if the scope is used, to avoid compartment syndromes that will have serious consequences for the patients. The senior author (SA) on more than one occasion has suspended the arthroscopic procedure of repair / reinsertion of the cruciate ligaments due to an unusual increase in the pressure of the compartments and has had to change to the open approach or stage. For irreparable interstitial lesions of the major KDIV ligaments that require reconstructive procedures, it is advisable to perform it as a late surgery after 3 or 4 weeks in a single surgical time to decrease the risk of compartment syndrome and soft tissue problem healing.

The Fifth controversy refers whether it is better to repair than to reconstruct the ligaments and starting for the posterolateral corner, an attempt has been made to generate a consensus [14] with experts regarding the diagnosis, treatment and rehabilitation of these lesions. Different authors such as Stannard et al. [105] in a comparative study between isolated repair versus reconstruction have shown a failure rate greater than $37 \%$ versus 9\% when repaired, just as Levy et al. in an article already cited found greater failures with repair than with reconstruction. Geeslin et al. [32] in another systematic level IV review, analyze the results of acute repair of the posterolateral corner and conclude that the failure rate is high when cruciate surgery is performed in a second stage. Conversely, Westermann et al. [120] in a multicenter comparative study between repair and reconstruction found no differences in functional scales. For the authors of this article, the results shown in the literature besides to be variables, have low evidence, therefore no conclusions can be given. In early-intervened PLC injuries, which are usually type $\mathrm{B}$ and $\mathrm{C}$ lesions according to the Bleday and Fanelli classification [9], it is advisible repair / reinsert (Fig. 8. FCL avulsion) and augment with an allograft/auto using preferably the Arciero technique $[2,41,113]$ which it is enough to control the varus and external rotation, (Fig. 9. Arciero Technique) without the need to add another tunnel in the tibia [99], which increases the time and trauma of the tissues. In some circumstances there is associate a fibular head fracture that compromises any augmented reconstructive procedure in it (Fig. 10. Fibular Fracture). In late phase or chronic lesions, if a PCL lesion is associated, the authors recommend the Laprade reconstruction technique, because the graft that crosses the lateral tibial tunnel is synergistic with the PCL graft, maximizing the posterior stability of the knee (Fig. 11, Laprade tibial tunnel). In cases of combined ACL and PLC chronic injuries, the Arciero technique produce very good results.

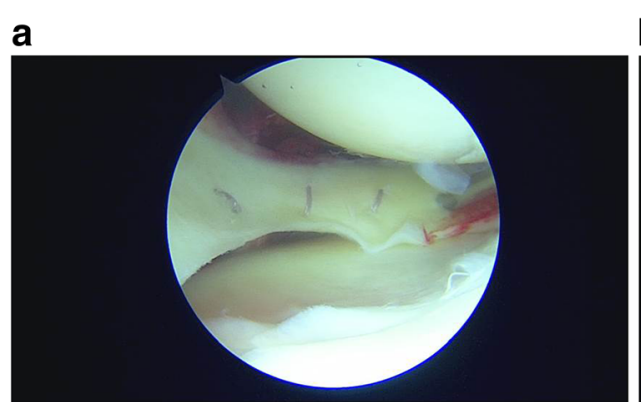

Fig. 7 a In-out meniscal repair. b $A C L$ Repair and Internal Brace

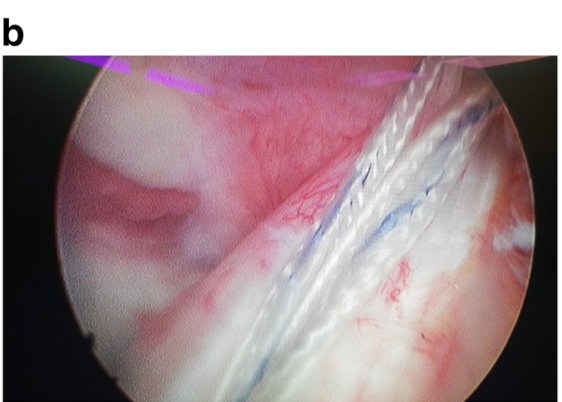




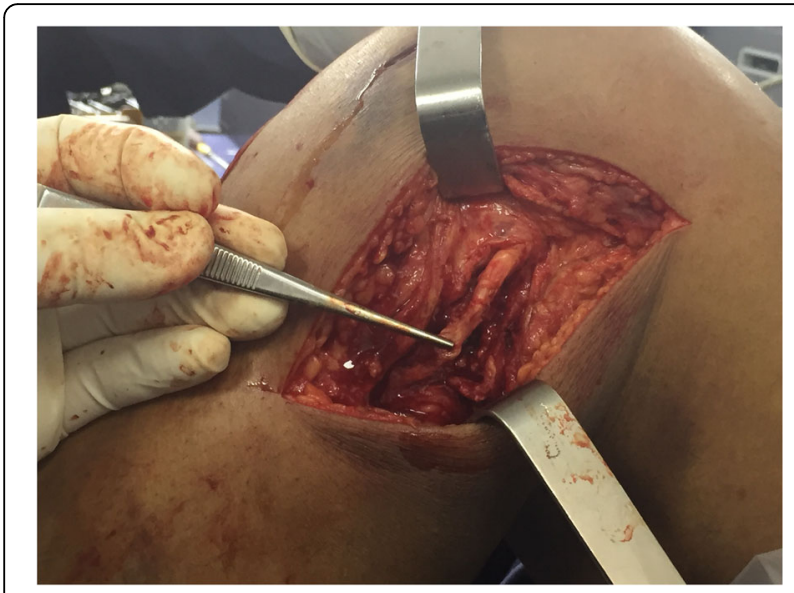

Fig. $8 \mathrm{FCL}$ avulsion

For the postero medial corner there is a consensus that these lesions can heal without surgery and that is why many schools wait 4 to 6 weeks and then only address cruciates ligaments after that. However, De Long [21] in a systematic review concludes that the repair of the posteromedial corner gives excellent results in terms of stability and function. Ferrari et al. [71] prefer in KD/ IIIM injuries, to reconstruct all structures in a single surgical time as well as Richter et al. [92] For the senior author, except for distal avulsions or entrapment ligament into the joint that are indicative of surgery, the postero-medial corner lesions heal properly without surgery as long as the limb is not loaded too early. If after 6 weeks the medial side is unstable in extension, he performs ligament capsule plication with excellent results comparable to reconstructive techniques and only in severe post-medial instability with insufficient original tissue, use Lind [66] or Laprade [71] techniques. The possibility of coalescence of tunnels with postero medial

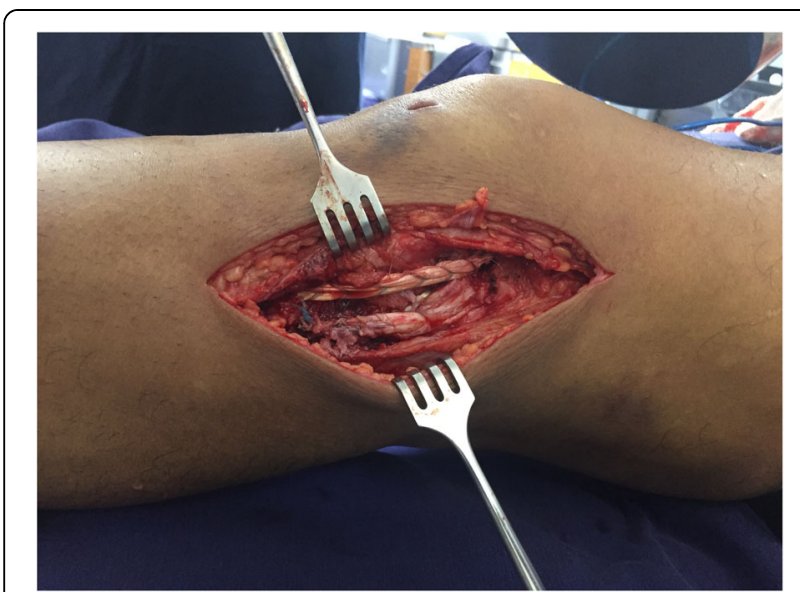

Fig. 9 Arciero Technique reconstructive surgery is high and hence some techniques have been described to avoid it [13, 77, 98]. The medial plication has the advantage of not using grafts, the tunnels are avoided, the original tissue is used and the original insertions are preserved. The senior author in 26 patients who had used this technique due to chronic medial instability, 24 patients had an excellent result according to the IKDC scale. One of the authors of this revision $(\mathrm{AJ})$, use just one femoral tunnel in case of MCL reconstruction to diminish the complications described before and having good results.

The senior author in KDIV lesions that need be operated early to repair the PLC, the medial side is left alone without any surgical gesture and at the most, the tissue is augmented with ultra-high tension sutures tapes following the principles of the internal brace $[45,75]$. There is also controversial if it is better to repair the cruciate ligaments than to reconstructed although different systematic reviews have shown similar results. Heitmann et al. [39], in 69 knee dislocations who had both cruciates repaired and augmented with high tension sutures, obtained $87.5 \%$ of good results according to the Lysholm scale. Kohl et al. [55], in 35 patients with MLKI, obtained $82 \%$ of good results using for the ACL the Dynamic intraarticular System (DIS, Lygamis ${ }^{\mathrm{TM}}$ ), and repairing the PCL and the corners. On the senior author experience, many of the cruciates injuries in MLKI preserve remnants, (Fig. 12a. ACL proximal rupture), (Fig. 12b,MRI proximal ACL rupture) (Fig. 12c. Proximal PCL rupture) preferably indicating ligament repair / reinsertion over reconstruction (Fig. 13a. Proximal ACL repair) (Fig. 13b. Distal ACL repair), with internal brace augmentation, using high tension sutures with independent fixation $[18,49]$ or use biological augmentation with autografts (Fig. 14. ACL repair and Biological augmentation) (Fig. 15. PCL Postero medial Biological Augmentation). In the absence of remnants, the article authors prefer use of autografts, taking preferentially the hamstrings of both legs (Fig. 16. Four Hamstrings).

The Sixth controversy refers to the type of grafts to be used. There is no comparative study that demonstrates any superiority of autografts versus allografts in the treatment of MLKI, but in general the use of the latter is preferred because decrease tissue trauma and surgical time, getting good results regarding to the stability and function $[7,17,100,108]$ however with the use of allografts has been reported greater risk of infection transmission, rejection, and early failure [51, 111]. Franciozi et al. [28] in a case series study, report good results using autos with hamstrings in early MKL surgery. In the experience of the senior author, allografts are a good alternative because of the advantages already stated, but it has been reported high failure in cruciate reconstruction specially in young and active patients. 


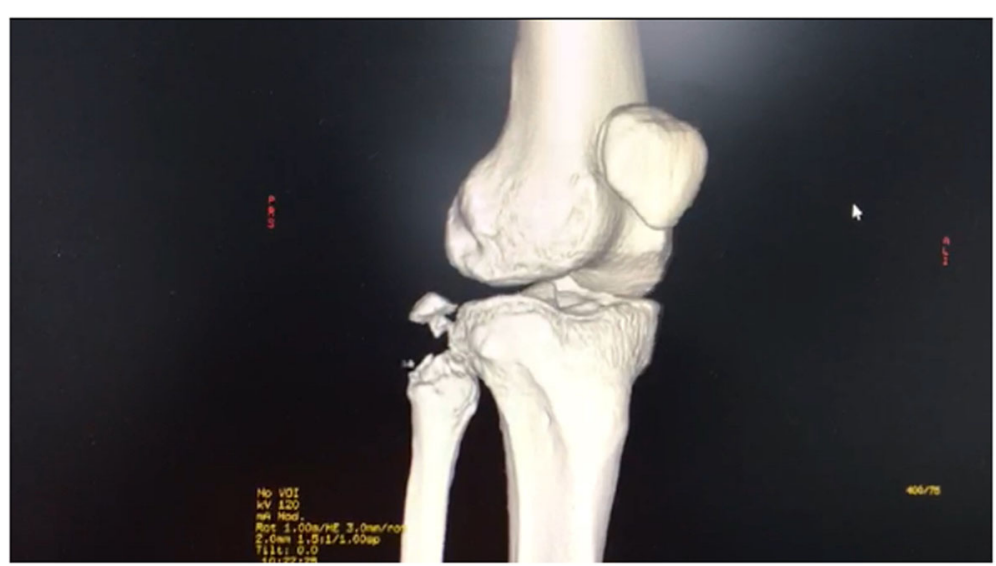

Fig. 10 Fibular Fracture

Even in industrialized countries, allografts are not always available, so surgeons we have to take the patient's tendons, in that sense, the author article recommend the use of the two-leg hamstrings, (Fig. 17. Both leg harvested) minimizing trauma of the affected knee, and decreasing the possibility of failure of the intra-articular surgery reported with the use of allografts, taking into account that most of these patients are young adults, who are going to be exposed to heavy loads in their

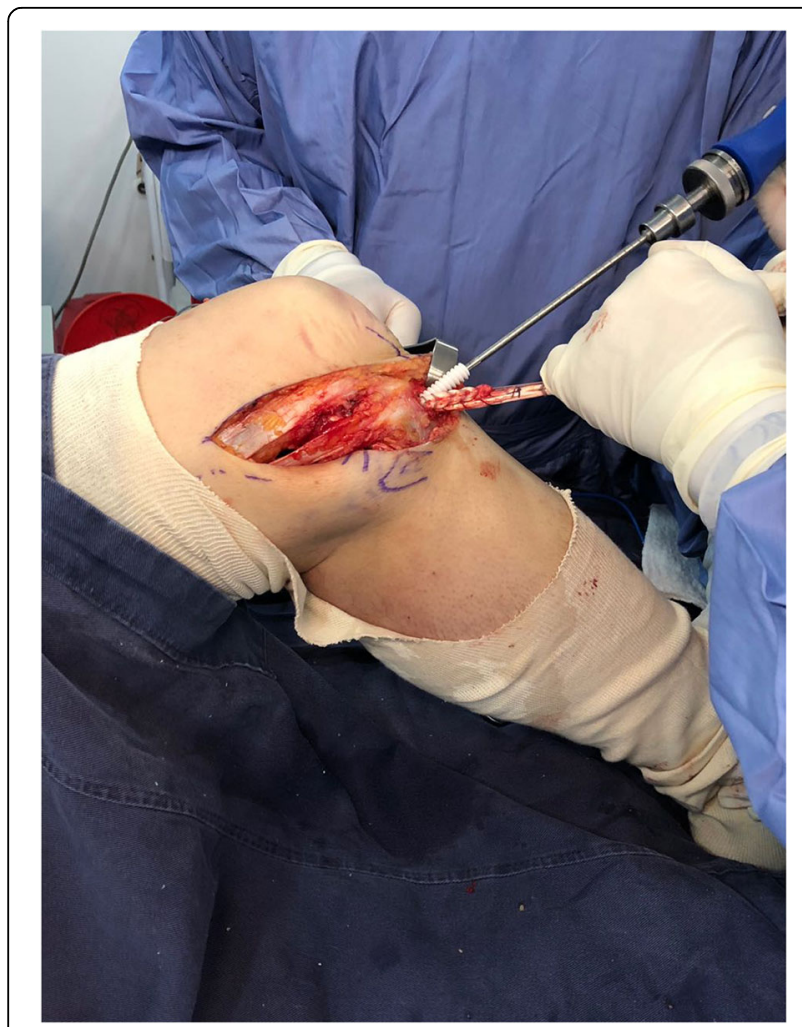

Fig. 11 Laprade tibial tunnel work and / or sports life. Some authors use synthetic grafts type LARS [91] (Ligament advanced Reinforced System ${ }^{\mathrm{m}}$ ). Gliatis et al. [48] in a retrospective study of 31 cases report good results using it for PCL in acute cases with the advantage of a smaller surgical trauma and faster return to work activity. Ranger et al., in 111 acute MLKI lesions also used LARS, obtaining $90 \%$ of good and excellent results when they reconstructed the ACL and the corners but only $60 \%$ of the patients with PCL reconstruction obtained good results. Chiang et al. [15] in a case series study in 33 patients found partial rupture of the LARS in a 10-year follow-up, therefore they do not recommend it.

The Seventh controversy refers to the sequence of graft fixation. There is no solid evidence in the literature that supports the best protocol for sequential graft fixation in multi-ligament knee surgery. It has been traditional to first fix the PCL as the central axis of rotation of the knee and main stabilizer [78], however in recent publications made in cadaver studies, it has been seen that tensioning the two cruciates and fixing the ACL first, reproduces better the kinematics of the knee [29, 126] . Kim et al. [53], in a series of case studies in 25 patients with KDII / III / IV, used first tensioning and fixation protocol of the PCL in 14 patients and in 11 both cruciates were tensioned at the same time and fixed the ACL first, obtaining in this last, better posterior stability and functional scales. In the opinion of the senior author, in injuries of the two cruciates, if the PCL is first fixed, without tensioning of ACL graft, there is a risk of fixing the knee not in a neutral position but anterior, generating a tension in PCL graft, which can cause elongation and fail over time. The senior author, currently in KDII/IIIL and KDIV lesions, follows the principles of Kim study tensioning both cruciates, fixing the ACL first, then the PCL, PLC and finally PMC. For the time being, having no randomized prospective 


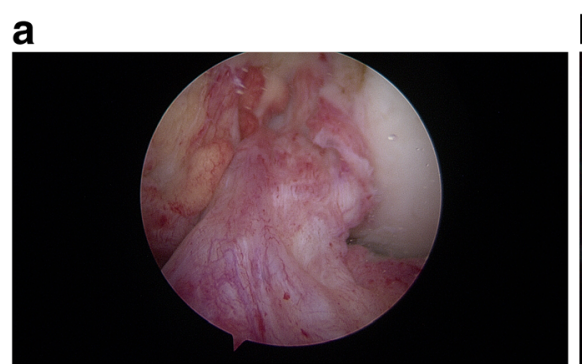

b

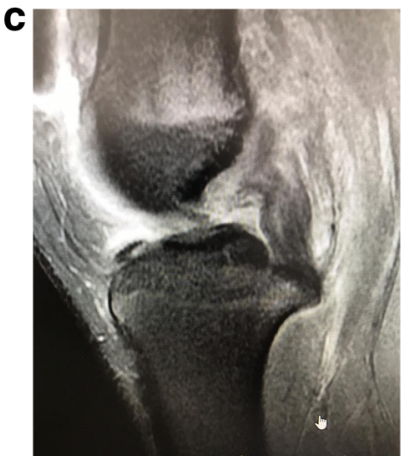

Fig. 12 a $A C L$ proximal rupture. b MRI proximal $A C L$ rupture. c Proximal $P C L$ rupture

comparative clinical studies, the fixation sequence will remain subjective and dependent on the surgeon.

The Eighth controversy has not been much debated in the literature specifically in the context of multiligament surgery of the knee and refers to whether the results in terms of functional scales are better if "anatomical" techniques are made for the reconstruction of the collateral ligaments and for the cruciates, this last with the use of double tunnel. For PLC reconstruction, in cadaver studies conducted by Treme et al. [113], both the Arciero and LaPrade techniques showed similar behavior in terms of varus control and external rotation. In clinical studies the two techniques have also been compared with similar results $[114,115]$ however other authors such as Kandeel [50] perform non-anatomical biceps tenodesis surgery with results comparable to the techniques described. Little attention has been made about the Postero medial corner but there is a trend to reconstruct the POL and $M C L$ instead of the MCL alone. In PCL reconstruction surgery, the literature referring to the advantages of some reconstructive technique over another is very poor, however in a systematic review in cadaver studies, Lee et al. [62] found that the double bundle gives more posterior stability than a one bundle. Maradei-et al [69] found that the technique of a one bundle with a thick graft is superior to the double bundle. $\mathrm{Xu}$ et al. [124] in a prospective comparative study in 59 patients, found no differences between the two techniques. In the authors article opinion, since there is no significant difference between the two techniques and in the multiligament surgery scenario where trauma and surgical time count, recommends the reconstruction of anterolateral band of the PCL with a tick graft, and central-central ACL, reducing trauma and a

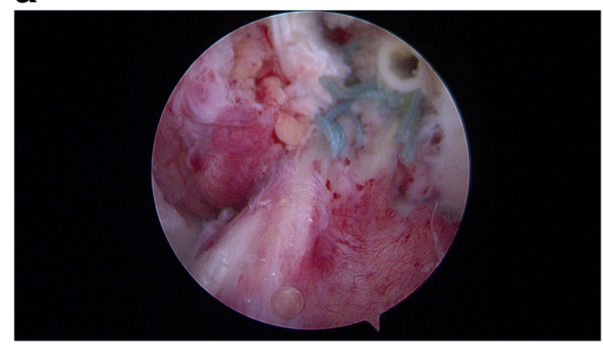

b

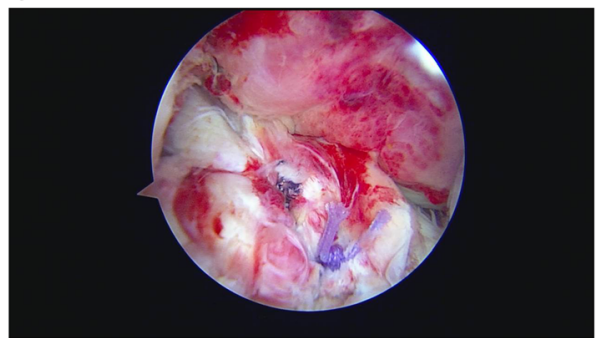

Fig. 13 a. Proximal ACL repair. b. Distal ACL repair 


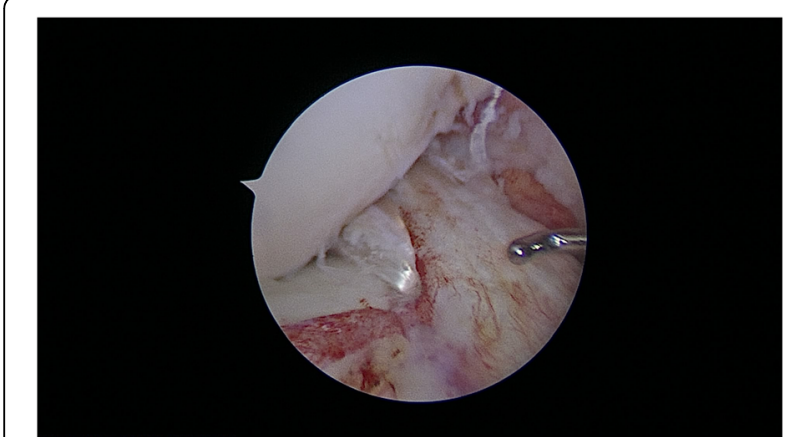

Fig. $14 \mathrm{ACL}$ repair and Biological augmentation

time. (Fig. 18. PCL and ACL one bundle reconstruction). It is noteworthy that the most of the PCL's injuries that accompany the MLKI are accompanied by a good remnant that can be repaired/reinserted, and augmented with high-tension sutures or grafts.

The Ninth controversy refers to performing coronal or sagittal realignment procedures before reparative or reconstructive ligament surgery. In general, there is a consensus that established chronic multi-directional instabilities, with varus alignments that are exaggerated with gait, such as varus thrust, realignment osteotomy is mandatory to subsequently protect the reconstruction of the corner [6, 12, 81] Noyes et al. [83, 84] found that one of the failures in PLC surgery is not to correct the varus. Arthur et al. [4], in a prospective study in 21 patients with posterolateral instability, found that tibia valguizing osteotomy was effective and $38 \%$ of them did not need a second procedure when instability was not severe. Tischer et al. [112] in a systematic review found that the coronal and sagittal angular deformities constitute a failure factor in uni and multiligamentary surgery and that in addition the re-aligning surgery is effective in the treatment of posterolateral instability and in ACL revision surgery. There is no literature support to back up an osteotomy for valgus deformity in PM instability. In what exists controversy is whether it is indicated to do these procedures in acute phase in patients with gross

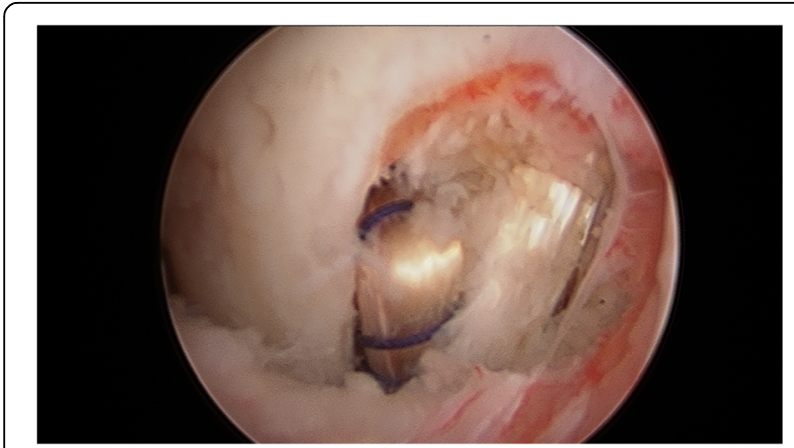

Fig. 15 PCL Postero medial Biological Augmentation

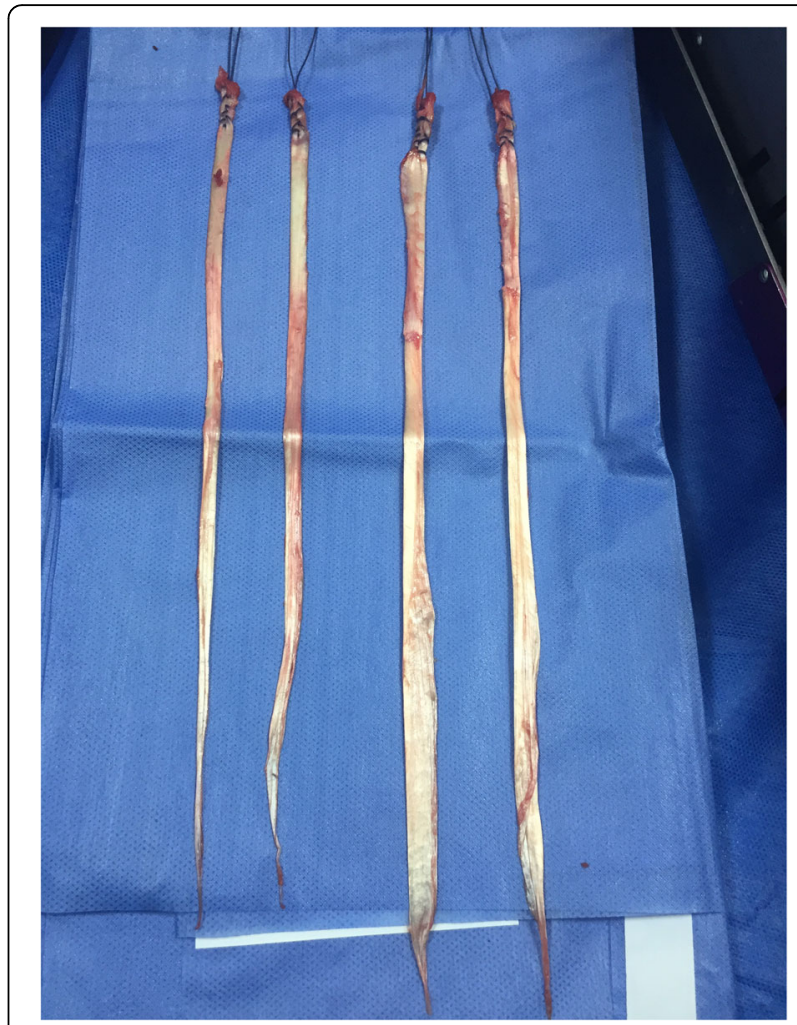

Fig. 16 Four Hamstrings

angular deformities especially in varus deformities with injuries of the Posterolateral corner. The literature is extremely poor in this regard and in general surgeons do not indicate it, but the authors article consider that the acute condition does not change the risk factor and failure in posterolateral and posteromedial instability with varus or valgus deformity, therefore, they performs osteotomy as the first surgical procedure in the setting of acute cases with moderate to severe angular deformities (Fig. 19a. High Varus deformity), (Fig. 19b. POP valgus

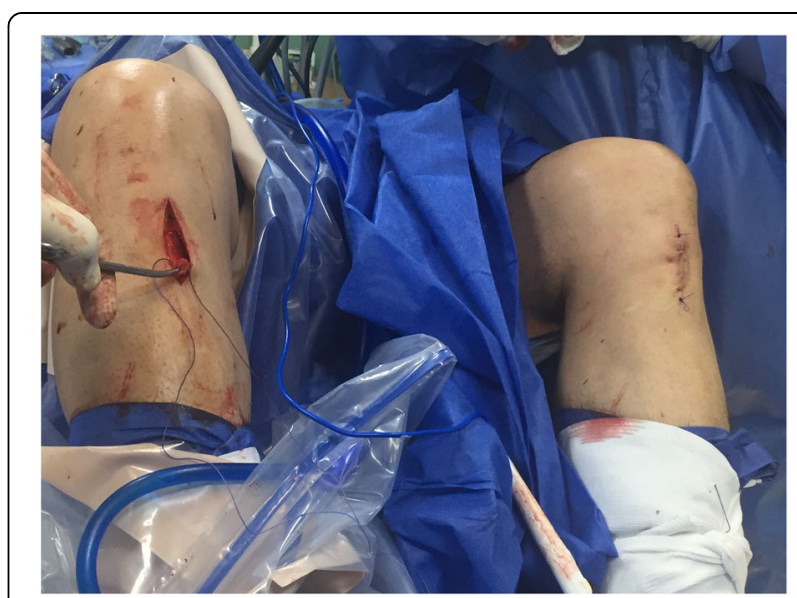

Fig. 17 Both leg haversted 


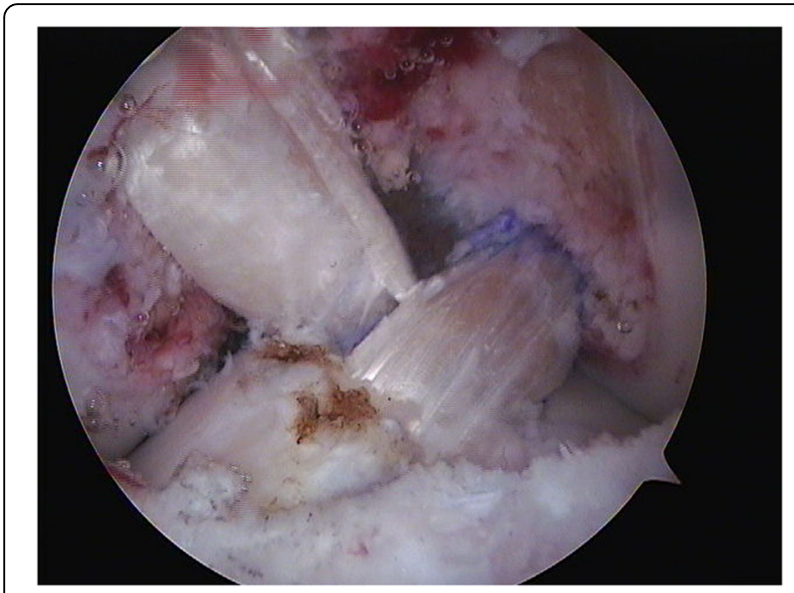

Fig. $18 P C L$ and $A C L$ one bundle reconstruction

osteotomy). In this scenario, osteotomy is performed after the patient recover full knee motion and in some selected cases, especially in young patients, the osteotomy could be performed at the same time with the ligament reconstruction avoiding a second stage procedure.

The Tenth and final controversy refers to rehabilitation, as with surgical treatment, there is little evidence of the ideal rehabilitation program. In general in reparative surgery it is preferred to protect the structures by delaying the beginning of mobility and in reconstructions where rigid implants are used, early motion is allowed $[65,105]$. Irrgang et al. [44], recommend that rehabilitation protocols should be individualized taking into account the repaired or reconstructed tissue, and the fixation used. Some authors such as Skendzel [103] and Edson [23] advocate conservative protocols that delay mobility and support, to allow good healing and joint

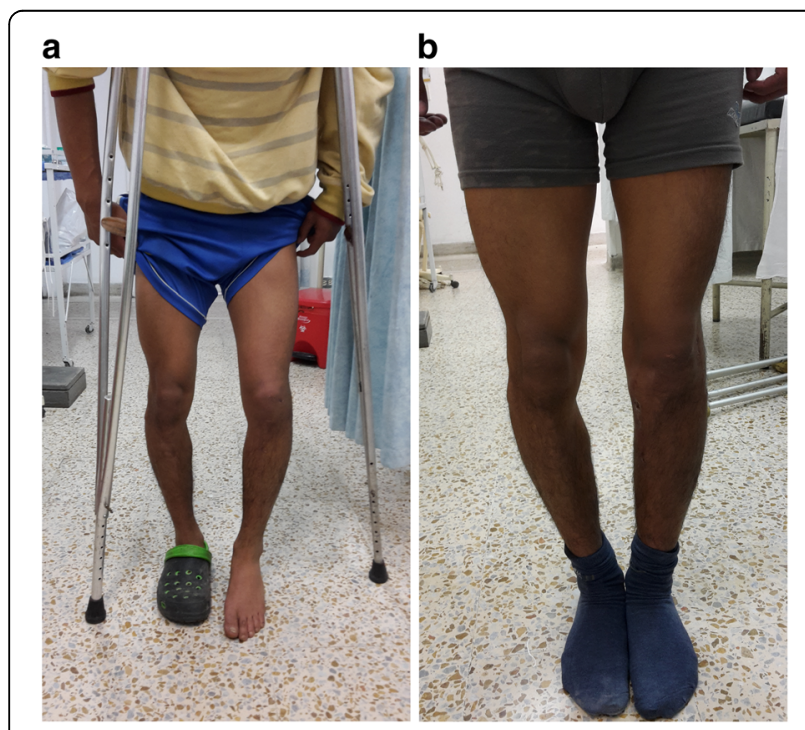

Fig. 19 a. High Varus deformity. b POP valgus osteotomy stability. Others like Stannard [105], Noyes [85], and Hubert [43] recommend reconstructive surgery with early motion to avoid complications such as arthrofibrosis which is common in this type of surgery. Mook [79] in a systematic review found that patients operated acutely have more chance of develop arthrofibrosis than late or two-stage surgery and therefore recommends an aggressive rehabilitation program in patients undergoing multiligament repair surgery. There are variable and low scientific evidence studies that deal with the effect of weight bearing in Multiligament surgery, some recommend late support after 6 weeks $[22,26,46]$ others immediate partial support and some more aggressive early support without restrictions [44]. Mosquera et al. [80], in a prospective randomized study in 20 patients who had undergone reconstructive corner surgery found that early support affected joint stability in posterolateral corner surgery but not in the posteromedial side. Conversely, LaPrade et al. [61] in a randomized prospective study in 36 patients who had undergone reconstruction of the PLC, found no differences in stability and function at 6 months post-surgery, therefore recommend early support. Finally, although there are reports of patients who have managed to return to their same sport level [57, 104]. Everhart et al. [24] in a systematic review in 26 studies with 524 patients found that the return of high competition sports in multiligament surgery is very low and varies between 22 and 33\%. The Authors of this article promote early passive motion starting next day after surgery encouraging knee extension and allowing partial weight bearing after three weeks when corners were addressed. In bicruciate surgery early support is stimulated as soon as the patient tolerates it. Finally in this complex pathology return to contact sports is discouraged to the non-professional athletes. Competitive professional athletes have other motivations that go beyond medical advice (Table 1).

\section{Conclusions}

According to the reviewed literature, most of the articles that refer about the general controversies in the diagnosis and treatment of MLKI lesions are cases series with a low level of clinical evidence. The only topic that there is a currently consensus is that surgical treatment offers better functional results and return to work and sports activity than non-surgical treatment. There is a tendency to intervene early these patients in one stage surgical time, repairing collateral lesions when it allowed and preferably using allografts in ligament reconstructions KDII / III / IV injuries. There is also a trend to use high strength sutures in intra and extra-articular ligament repairs as augmentation, with results similar to reconstructive techniques, reducing the morbidity generated by the latter. Open surgery for collateral lesions remains the gold standard but there is a tendency to use less 
Table 1 The 10 recommendations for the Orthopedist dealing with the Treatment of Acute MLKI Injuries

1 Always work as a team In the Emergency Room. Two heads think more than one.

2 Always, in all cases, rule out a Vascular lesion with accurate tests. Pedal pulse may not be your best friend.

3 Always in all cases, rule out a Peroneal Nerve injury with clinical test. The exam of the other leg will help you to diagnose partial injuries.

4 Always use an external fixator after a vascular repair. Use hinged if is available. Control Motion is better than not.

5 Always accompany yourself in surgery with trained personnel. This is not a 5 min surgery.

6 Always reinsert/repair the ligaments avulsions early. The best graft will never be better than the original tissue. Have high strength sutures, tapes, anchors, knotless on hand.

7 Always use appropriate measures to reduce surgical trauma in acute surgery. Use allografts instead autografts. Apply anatomical principles to repair /reconstructed ligaments. Remember than in this complex situation, the simple is better.

8 Always recover joint motion as soon as possible. Stiffness has a worse prognosis than residual instability.

9 Always Correct dynamic or severe angular deformity in chronic cases, before ligaments reconstruction. A varus knee deformity will spoil out your best PLC reconstruction.

10 Always remember that these lesions are not comparable in their results with mono-ligamentary surgery. Probably patients never will go back to their same level work and sports. Do not forget to explain them and family.

invasive arthroscopic techniques with similar results with the concept of anatomy reproduction. The importance of coronal and sagittal angular deformities is recognized as a factor of failure in chronic multi-ligament surgery and therefore osteotomies are increasingly indicated before ligament reconstruction, however in the setting of the acute trauma, osteotomy is not accepted for the majority of surgeons. Finally, rehabilitation protocols tend to encourage early mobility and early support with better functional results for patients.

\section{Abbreviations}

ACL: Anterior cruciate Ligament; CTA: Angio TAC; IKDC: International Knee Documentation Committee; KD: Knee dislocation; LARS: Ligament advanced reinforced system; MLKI: Multi Ligament Knee injuries; PCL: Posterior cruciate Ligament; PLC: Postero Lateral Corner; PMC: Postero medial corner; PM: Postero medial

\section{Authors' contributions}

Alejandro Jaramillo MD, Ricardo Gil MD, Yessica Gonzalez PT. Correspondence to Senior Author: Manuel Mosquera MD. Email: mosco61 @gmail.com. The author(s) read and approved the final manuscript.

\section{Funding}

No funding were collected to carry out this Expert opinion.

\section{Competing interests}

The authors of this article declare have not conflict of interest.

\section{Author details}

${ }^{1}$ Clinica Erasmo, Valledupar, Colombia. ${ }^{2}$ Clinica La Carolina, Carrera 14 \# 127-11 Cons 307-308, Bogota, Colombia. ${ }^{3}$ Clinica Del Norte, Medellin, Colombia.

Received: 1 April 2020 Accepted: 8 June 2020

Published online: 27 July 2020

\section{References}

1. Angelini FJ, Helito CP, Bonadio MB, Guimarães TM, Barreto RB, Pécora JR, Camanho GL, da Mota E Albuquerque RF. (2015) External fixator for treatment of the sub-acute and chronic multi-ligament-injured knee. Knee Surg Sports Traumatol Arthrosc 23(10):3012-3018

2. Arciero RA (2005) Anatomic posterolateral corner knee reconstruction. Arthroscopy 21(9):1147
3. Arom GA, Yeranosian MG, Petrigliano FA, Terrell RD, McAllister DR (2013) The changing demographics of knee dislocation: a retrospective database review. Clin Orthop Relat Res

4. Arthur A, LaPrade RF, Agel J (2007) Proximal tibial opening wedge osteotomy as the initial treatment for chronic posterolateral corner deficiency in the varus knee: a prospective clinical study. Am J Sports Med 35:1844-1850

5. Azar FM, Brandt JC, Miller RH 3rd, Phillips BB (2011) Ultra-low-velocity knee dislocations. Am J Sports Med 39(10):2170-2174

6. Badhe NP, Forster IW (2002) High tibial osteotomy in knee instability: the rationale of treatment and early results. Knee Surg Sports Traumatol Arthrosc 10:38-43

7. Billières J, Labruyère $C$, Steltzlen $C$, Gonzalez $A$, Boisrenoult $P$, Beaufils $P$, Pujol N (2019) Multiligament knee injuries treated by one-stage reconstruction using allograft: postoperative laxity assessment using stress radiography and clinical outcomes. Orthop Traumatol Surg Res

8. Bin SI, Nam TS (2007) Surgical outcome of 2-stage management of multiple knee ligament injuries after knee dislocation. Arthroscopy. 23:1066-1072

9. Bleday RM, Fanelli GC, Giannotti BF, Edson CJ, Barrett TA (1998) Instrumented measurement of the posterolateral corner. Arthroscopy. 14: 489-494

10. Boisrenoult $P$, Lustig $S$, Bonneviale $P$, Leray $E$, Versier $G$, Neyret $P$, Rosset $P$, Saragaglia D (2009) Vascular lesions associated with bicruciate and knee dislocation ligamentous injury. French Society of Orthopedic Surgery and Traumatology (SOFCOT). Orthop Traumatol Surg Res 95(8):621-626

11. Brautigan B, Johnson DL (2000) The epidemiology of knee dislocations. Clin Sports Med 19(3):387-397

12. Cantin O, Magnussen RA, Corbi F, Servien E, Neyret P, Lustig S (2015) The role of high tibial osteotomy in the treatment of knee laxity: a comprehensive review. Knee Surg Sports Traumatol Arthrosc 23:3026-3037

13. Chahla J, Arroquy D, Vilaseca T, Carboni M, Mitchell JJ, Dean CS, Cinque ME, Rodeo SA, Pascual-Garrido C (2017) Minimally invasive anatomical reconstruction of posteromedial corner of knee: a cadaveric study. Am J Orthop (Belle Mead NJ) 46(6):E429-E434

14. Chahla J, Murray IR, Robinson J, Lagae K, Margheritini F, Fritsch B, Leyes M, Barenius B, Pujol N, Engebretsen L, Lind M, Cohen M, Maestu R, Getgood A, Ferrer G, Villascusa S, Uchida S, Levy BA, Von Bormann R, Brown C, Menetrey J, Hantes M, Lording T, Samuelsson K, Frosch KH, Monllau JC, Parker D, LaPrade RF, Gelber PE (2019) Posterolateral corner of the knee: an expert consensus statement on diagnosis, classification, treatment, and rehabilitation. Knee Surg Sports Traumatol Arthrosc 27(8):2520-2529

15. Chiang LY, Lee CH, Tong KM, Wang SP, Lee KT, Tsai WC, Chen CP (2019) Posterior cruciate ligament reconstruction implemented by the ligament advanced reinforcement system over a minimum follow-up of 10 years. Knee

16. Chowdhry M, Burchette D, Whelan D, Nathens A, Marks P, Wasserstein D (2019) Knee dislocation and associated injuries: an analysis of the American College of Surgeons National Trauma Data Bank. Knee Surg Sports Traumatol Arthrosc 
17. Cook S, Ridley TJ, McCarthy MA, Gao Y, Wolf BR, Amendola A et al (2015) Surgical treatment of multiligament knee injuries. Knee Surg Sports Traumatol Arthrosc 23:2983-2991

18. Dabis J, Wilson A (2019) Repair and augmentation with internal brace in the multiligament injured knee. Clin Sports Med 38(2):275-283

19. Hankins DA, Fletcher IE, Prieto F, Ockuly AC, Myers OB, Treme GP, Veitch AJ, Wascher DC, Schenck RC, Richter DL (2019) Critical evaluation of the methodologic quality of the top 50 cited articles relating to knee dislocation and multiligamentous knee injury. Orthop J Sports Med 7(11)

20. Dedmond BT, Almekinders LC (2001) Operative versus nonoperative treatment of knee dislocations: a meta-analysis. Am J Knee Surg 14(1):33-38

21. DeLong JM, Waterman BR (2015) Surgical repair of medial collateral ligament and posteromedial corner injuries of the knee: a systematic review. Arthroscopy. 31(11):2249-2255

22. Edson CJ, Fanelli GC, Beck JD (2011) Rehabilitation after multiple-ligament reconstruction of the knee. Sports Med Arthrosc Rev 19(2):162-166

23. Edson CJ (2006) Conservative and postoperative rehabilitation of isolated and combined injuries of the medial collateral ligament. Sports Med Arthrosc Rev 14(2):105-110

24. Everhart JS, Du A, Chalasani R, Kirven JC, Magnussen RA, Flanigan DC (2018) Return to work or sport after multiligament knee injury: a systematic review of 21 studies and 524 patients. Arthroscopy. 34(5):1708-1716

25. Fanelli GC (2019) Multiple ligament injured knee: initial assessment and treatment. Clin Sports Med 38(2):193-198

26. Fanelli GC, Edson CJ, Reinheimer KN, Garofalo R (2007) Posterior cruciate ligament and posterolateral corner reconstruction. Sports Med Arthrosc 15(4):168-175

27. Ferraresi S, Garozzo D, Buffatti P (2003) Common peroneal nerve injuries: results with one-stage nerve repair and tendon transfer. Neurosurg Rev 26:175-179

28. Franciozi CE, Albertoni LJB, Kubota MS, Abdalla RJ, Luzo MVM, Cohen M, LaPrade RF (2019) A hamstring-based anatomic posterolateral knee reconstruction with autografts improves both radiographic instability and functional outcomes. Arthroscopy. 35(6):1676-1685

29. Franciozi CE, de Carvalho RT, Itami Y, McGarry MH, Ingham SJM, Abdalla RJ, Tibone JE, Lee TQ (2019) Bicruciate lesion biomechanics, part 2-treatment using a simultaneous tensioning protocol: ACLfixation first is better than PCL fixation first to restore tibiofemoral orientation. Knee Surg Sports Traumatol Arthrosc 27(9):2936-2944

30. Garozzo D, Ferraresi S, Buffatti P (2002) Common peroneal nerve injuries in knee dislocations: results with one-stage nerve repair and tibialis posterior tendon transfer. J Orthop Traumatol 2:135-137

31. Garozzo D, Ferraresi S, Buffatti $P$ (2004) Surgical treatment of common peroneal nerve injuries: indications and results. A series of 62 cases. J Neurosurg Sci 48:105-112

32. Geeslin AG, Moulton SG, LaPrade RF (2016) A systematic review of the outcomes of posterolateral corner knee injuries, part 1: surgical treatment of acute injuries. Am J Sports Med 44(5):1336-1342

33. Georgiadis AG, Mohammad FH, Mizerik KT, Nypaver TJ, Shepard AD (2013) Changing presentation of knee dislocation and vascular injury from high-energy trauma to low-energy falls in the morbidly obese. J Vasc Surg 57:1196-1203

34. Moatshe G, Dornan GJ, Løken S, Ludvigsen TC, LaPrade RF, Engebretsen L (2017) Demographics and injuries associated with knee dislocation: a prospective review of 303 patients. Orthop J Sports Med, May 5(5)

35. Goitz RJ, Tomaino MM (2003) Management of peroneal nerve injuries associated with knee dislocations. Am J Orthop (Belle Mead NJ) 32:14-16

36. Gousheh J, Babaei A (2002) A new surgical technique for the treatment of high common peroneal nerve palsy. Plast Reconstr Surg 109:994-998

37. Green NE, Allen BL (1977) Vascular injuries associated with dislocation of the knee. J Bone Joint Surg Am 59:236-239

38. Harner CD, Waltrip RL, Bennett CH (2004) Surgical management of knee dislocations. J Bone Joint Surg 86A:262-273

39. Heitmann M, Akoto R, Krause M, Hepp P, Schöpp C, Gensior TJ, Bartl C, Lill $\mathrm{H}$, Frosch KH (2019) Management of acute knee dislocations: anatomic repair and ligament bracing as a new treatment option-results of a multicentre study. Knee Surg Sports Traumatol Arthrosc 27(8):2710-2718

40. Hirschmann MT, Iranpour F, Muller W, Friederich NF Surgical treatment of complex Bicruciate knee ligament injuries in elite athletes: what Long-term outcome can we expect? Am J Sports Med

41. Ho EP, Lam MH, Chung MM et al (2011) Comparison of 2 surgical techniques for reconstructing posterolateral corner of the knee: a cadaveric study evaluated by navigation system. Arthroscopy. 27(1):89-96
42. Hoit G, Farag J, Whelan DB (2019) Neurologic assessment and management of the multiple ligament injured knee: a review and synthesis of current evidence. J Knee Surg.

43. Hubert MG, Stannard JP (2011) Surgical treatment of acute and chronic anterior and posterior cruciate ligament and medial-side injuries of the knee. Sports Med Arthrosc Rev 19(2):104-109

44. Irrgang JJ, Fitzgerald GK (2000) Rehabilitation of the multiple-ligamentinjured knee. Clin Sports Med 19(3):545-571

45. Lubowitz JH, MacKay G, Gilmer B (2014) Knee medial collateral ligament and posteromedial corner anatomic repair with internal bracing. Arthrosc Tech 3(4):e505-e508

46. Jenkins PJ, Clifton R, Gillespie GN, Will EM, Keating JF (2011) Strength and function recovery after multiple-ligament reconstruction of the knee. Injury. 42(12):1426-1429

47. Jiang W, Yao J, He Y, Sun W, Huang Y, Kong D (2015) The timing of surgical treatment of knee dislocations: a systematic review. Knee Surg Sports Traumatol Arthrosc 23(10):3108-3113

48. Gliatis J, Anagnostou K, Tsoumpos P, Billis E, Papandreou M, Plessas S (2018) Complex knee injuries treated in acute phase: long-term results using ligament augmentation and reconstruction system artificial ligament. World J Orthop 9(3):24-34

49. Jonkergouw A, van der List JP, DiFelice GS (2018) Multiligament repair with suture augmentation in a knee dislocation with medial-sided injury. Arthrosc Tech 7(8):e839-e843

50. Kandeel AA (2019) Biceps femoris tenodesis revisited a prospective cohort study of concurrent anterior cruciate and postero-lateral corner reconstruction. Injury.

51. Kåre Amtoft Nissen, Niclas Højgaard Eysturoy, Torsten Grønbech Nielsen, Martin Lind. Allograft use results in higher re-revision rate for revision anterior cruciate ligament reconstruction.

52. Frosch K-H, Preiss A, Heider S, Stengel D, Wohlmuth $P$, Hoffmann MF, Lill H (2013) Primary ligament sutures as a treatment option of knee dislocations: a meta-analysis. Knee Surg Sports Traumatol Arthrosc 21(7):1502-1509

53. Kim SJ, Kim SH, Jung M, Kim JM, Lee SW (2015) Does sequence of graft tensioning affect outcomes in combined anterior and posterior cruciate ligament reconstructions? Clin Orthop Relat Res 473(1):235-243

54. Knee dislocations: a meta-analysis. [Erratum appears in Am J Knee Surg 2001 Autumn; 144220]. Am J Knee Surg. 2001;14(1):33-8

55. Kohl S, Stock A, Ahmad SS, Zumstein M, Keel M, Exadaktylos A, Kohlhof H, Eggli S, Evangelopoulos DS (2015) Dynamic intraligamentary stabilization and primary repair: a new concept for the treatment of knee dislocation. Injury. 46(4):724-728

56. Kolosky M, Spindler KP (2018) A National Collegiate Athletic Association Division I Athlete's return to play after traumatic knee dislocation with vascular and nerve injury. J Am Acad Orthop Surg Glob Res Rev 2(11)

57. Kolosky M, Spindler KP. A National Collegiate Athletic Association Division I Athlete's Return to Play After Traumatic Knee Dislocation With Vascular and Nerve Injury

58. Krych AJ, Giuseffi SA, Kuzma SA, Stuart MJ, Levy BA (2014) Is peroneal nerve injury associated with worse function after knee dislocation? Clin Orthop Relat Res 472:2630-2636

59. Lachman JR, Rehman S, Pipitone PS (2015) Traumatic knee dislocations: evaluation, management, and surgical treatment. Orthop Clin North Am 46: 479-493

60. LaPrade RF, Chahla J, DePhillipo NN, Cram T, Kennedy MI, Cinque M, Dornan GJ, O'Brien LT, Engebretsen L, Moatshe G. Single-stage multipleligament knee reconstructions for sports-related injuries: outcomes in 194 patients

61. LaPrade RF, DePhillipo NN, Cram TR, Cinque ME, Kennedy MI, Dornan GJ, O'Brien LT (2018) Partial controlled early postoperative Weightbearing versus Nonweightbearing after reconstruction of the fibular (lateral) collateral ligament: a randomized controlled trial and equivalence analysis. Am J Sports Med 46(10):2355-2365

62. Lee DY et al (2017) Biomechanical comparison of single-bundle and double-bundle posterior cruciate ligament reconstruction: a systematic review and meta-analysis. JBJS Rev

63. McKee L, Ibrahim MS, Lawrence T, Pengas IP, Khan WS (2014) Current concepts in acute knee dislocation: the missed diagnosis? Open Orthop J 8:162-167

64. Levy BA, Dajani KA, Whelan DB (2009) Decision making in the multiligament-injured knee: an evidence-based systematic review. Arthroscopy. 25:430-438 
65. Levy BA, Dajani KA, Morgan JA, Shah JP, Dahm DL, Stuart MJ (2010) Repair versus reconstruction of the fibular collateral ligament and posterolateral corner in the multiligament-injured knee. Am J Sports Med 38(4):804-809

66. Lind M, Jakobsen BW, Lund B, Hansen MS, Abdallah O, Christiansen SE (2009) Anatomical reconstruction of the medial collateral ligament and posteromedial corner of the knee in patients with chronic medial collateral ligament instability. Am J Sports Med 37(6):1116-1122

67. López-Hualda A, Valencia-García H, Martínez-Martín J (2012) Vascular injuries associated with dislocation of the knee: diagnosis protocol. Rev Esp Cir Ortop Traumatol 56(4):260-266

68. Lucidi GA, Grassi A, Cucurnia I et al (2018) Use of external fixator pre- and post-reconstruction in the multiligament injured knee. Ann Joint 3:76

69. Maradei-Pereira JAR, Kokron AEV, Pereira CAM, Amatuzzi MM (2019) Thick graft versus double-bundle technique on posterior cruciate ligament reconstruction: experimental biomechanical study with cadavers. Rev Bras Ortop (Sao Paulo) 54(5):531-539

70. Marcacci M, Zaffagnini S, Bonanzinga T, Pizzoli A, Manca M, Caiaffa E (2012) Surgical technique: articulated external fixator for treatment of complex knee dislocation. Clin Orthop Relat Res 470(3):869-876

71. Ferrari MB, Chahla J, Mitchell JJ, Moatshe G, Mikula JD, Marchetti DC, LaPrade RF (2017) Multiligament reconstruction of the knee in the setting of knee dislocation with a medial-sided injury. Arthrosc Tech 6(2):e341-e350 Published online 2017 Mar 20

72. Maslaris A, Brinkmann O, Bungartz M, Krettek C, Jagodzinski M, Liodakis E (2018) Management of knee dislocation prior to ligament reconstruction: what is the current evidence? Update of a universal treatment algorithm. Eur J Orthop Surg Traumatol 28(6):1001-1015

73. Matthewson G, Kwapisz A, Sasyniuk T, MacDonald P (2019) Vascular injury in the Multiligament injured knee. Clin Sports Med 38(2):199-213

74. Medina O, Arom GA, Yeranosian MG, Petrigliano FA, McAllister DR (2014) Vascular and nerve injury after knee dislocation: a systematic review. Clin Orthop Relat Res 472(9):2621-2629

75. Mehl JT, Kia C, Murphy M, Obopilwe E, Cote M, Imhoff FB, Imhoff AB, Arciero RA, Beitzel K, Otto A (2019) Posteromedial ligament repair of the knee with suture tape augmentation: a biomechanical study. Am J Sports Med 47(12):2952-2959

76. Mills WJ, Barei DP, McNair P (2004) The value of the ankle-brachial index for diagnosing arterial injury after knee dislocation: a prospective study. J Trauma 56(6):1261-1265

77. Moatshe G, LaPrade RF, Engebretsen L (2018) How to avoid tunnel convergence in a multiligament injured knee. Ann Joint 3:93

78. Moatshe G, Chahla J, Brady AW, Dornan GJ, Muckenhirn KJ, Kruckeberg BM, Cinque ME, Turnbull TL, Engebretsen L, LaPrade RF (2018) The influence of graft tensioning sequence on tibiofemoral orientation during Bicruciate and posterolateral corner knee ligament reconstruction: a biomechanical study. Am J Sports Med 46(8):1863-1869

79. Mook WR, Miller MD, Diduch DR, Hertel J, Boachie-Adjei Y, Hart JM (2009) Multiple-ligament knee injuries: a systematic review of the timing of operative intervention and postoperative rehabilitation. J Bone Joint Surg Am 91(12):2946-2957

80. Mosquera M, Gonzalez J, Portilla D, Mosquera JM, Saurith O (2019) Afecta el apoyo temprano la estabilidad de la rodilla en cirugía de esquinas? Artroscopia 26(1):14-18

81. Naudie DD, Amendola A, Fowler PJ (2004) Opening wedge high tibial osteotomy for symptomatic hyperextension-varus thrust. Am J Sports Med 32:60-70

82. Niall DM, Nutton RW, Keating JF (2005) Palsy of the common peroneal nerve after traumatic dislocation of the knee. J Bone Joint Surg Br 87(5):664-667

83. Noyes FR, Barber-Westin SD, Albright JC (2006) An analysis of the causes of failure in 57 consecutive posterolateral operative procedures. Am J Sports Med 34:1419-1430

84. Noyes FR, Barber-Westin SD (2005) Posterior cruciate ligament revision reconstruction, part 1: causes of surgical failure in 52 consecutive operations. Am J Sports Med 33:646-654

85. Noyes FR, Barber-Westin SD (1997) Reconstruction of the anterior and posterior cruciate ligaments after knee dislocation. Use of early protected postoperative motion to decrease arthrofibrosis. Am J Sports Med 25(6):769-778

86. Ohkoshi Y, Nagasaki S, Shibata N, Yamamoto K, Hashimoto T, Yamane S (2002) Two-stage reconstruction with autografts for knee dislocations. Clin Orthop Relat Res:169-175

87. Owens BD, Neault M, Benson E, Busconi BD (2007) Primary repair of knee dislocations: results in 25 patients (28 knees) at a mean follow-up of four years. J Orthop Trauma 21(2):92-96
88. Peng PD, Spain DA, Tataria M, Hellinger JC, Rubin GD, Brundage SI (2008) CT angiography effectively evaluates extremity vascular trauma. Am Surgeon 74(2):103-107

89. Peskun CJ, Chahal J, Steinfeld ZY, Whelan DB (2012) Risk factors for peroneal nerve injury and recovery in knee dislocation. Clin Orthop Relat Res 470(3):774-778

90. Peskun CJ, Whelan DB (2011) Outcomes of operative and nonoperative treatment of multiligament knee injuries: an evidence-based review. Sports Med Arthrosc Rev 19(2):167-173

91. Ranger P, Renaud A, Phan P, Dahan P, De Oliveira E Jr, Delisle J (2011) Evaluation of reconstructive surgery using artificial ligaments in 71 acute knee dislocations. Int Orthop 35(10):1477-1482 Published online 2010 Nov 24

92. Richter D, Wascher DC, Schenck RC Jr. A novel posteromedial approach for tibial inlay PCL reconstruction in KDIIIM injuries: avoiding prone patient positioning

93. Richter M, Bosch U, Wippermann B, Hofmann A, Krettek C (2002) Comparison of surgical repair or reconstruction of the cruciate ligaments versus nonsurgical treatment in patients with traumatic knee dislocations. Am J Sports Med 30(5):718-727

94. Rihn JA, Groff YJ, Harner CD, Cha PS (2004) The acutely dislocated knee: evaluation and management. J Am Acad Orthop Surg 12(5):334-346

95. Samson D et al (2016) An evidence-based algorithm for the management of common peroneal nerve injury associated with traumatic knee dislocation. EFORT Open Rev

96. Schenck R, Burke R, Walker D (1992) The dislocated knee: a new classification system. South Med J 85:35S1

97. Schenck RC (1994) Jr the dislocated knee. Instr Course Lect 43:127-136

98. Selim NM (2019) Combined anterior cruciate ligament, medial collateral ligament, and posterior oblique ligament reconstruction through single Tibial tunnel using hamstring tendon autografts. Arthrosc Tech. 8(2):e163-e173

99. Serra Cruz R, Mitchell JJ, Dean CS, Chahla J, Moatshe G, LaPrade RF (2016) Anatomic posterolateral corner reconstruction. Arthrosc Tech. 5(3):563-572

100. Shapiro MS, Freedman EL (1995) Allograft reconstruction of the anterior and posterior cruciate ligaments after traumatic knee dislocation. Am J Sports Med 23:580-587

101. Shelbourne KD, Haro MS, Gray T (2007) Knee dislocation with lateral side injury: results of an en masse surgical repair technique of the lateral side. Am J Sports Med 35(7):1105-1116

102. Shelbourne KD, Porter DA, Clingman JA, McCarroll JR, Rettig AC (1991) Lowvelocity knee dislocation. Orthop Rev 20:995-1004

103. Skendzel JG, Sekiya JK, Wojtys EM (2012) Diagnosis and management of the multiligament-injured knee. J Orthop Sports PhysTher 42(3):234-242

104. Sonnery-Cottet B, Abreu FG, Saithna A, Ouanezar H, Fernandes LR, Fayard JM, Bulle S, Pedron O, Chambat P, Boisgard S (2019) Successful return to elite sport after bilateral knee dislocations: a case report. Orthop J Sports Med 7(5)

105. Stannard JP, Brown SL, Farris RC, McGwin G Jr, Volgas DA (2005) The posterolateral corner of the knee: repair versus reconstruction. Am J Sports Med 33(6):881-888

106. Stannard JP, Nuelle CW, McGwin G (2014) Volgas DA hinged external fixation in the treatment of knee dislocations: a prospective randomized study. J Bone Joint Surg Am 96(3):184-189

107. Stannard JP, Sheils TM, McGwin G, Volgas DA, Alonso JE (2003) Use of a hinged external knee fixator after surgery for knee dislocation. Arthroscopy. 19(6):626-631

108. Strauss MJ, Varatojo R, Boutefnouchet T, Condello V, Samuelsson K, Gelber PE, Adravanti P, Laver L, Dimmen S, Eriksson K, Verdonk P (2019) Spalding T the use of allograft tissue in posterior cruciate, collateral and multi-ligament knee reconstruction. Knee Surg Sports Traumatol Arthrosc 27(6):1791-1809

109. Subbiah M, Pandey V, Rao SK, Rao S (2011) Staged arthroscopic reconstructive surgery for multiple ligament injuries of the knee. J Orthop Surg (Hong Kong) 19:297-302

110. Taft T, Almekinders L (1994) The dislocated knee. In: Fu F, Harner C, Vince K (eds) Knee surgery. Williams \& Wilkins, Baltimore, pp 837-858

111. Tibor LM, Long JL, Schilling PL, Lilly RJ, Carpenter JE, Miller BS (2010) Clinical outcomes after anterior cruciate ligament reconstruction: a meta-analysis of autograft versus allograft tissue. Sports Health 2(1):56-72.

112. Tischer T, Paul J, Pape D, Hirschmann MT, Imhoff AB, Hinterwimmer S, Feucht MJ (2017) The impact of osseous malalignment and realignment procedures in knee ligament surgery: a systematic review of the clinical evidence. Orthop J Sports Med 5(3)

113. Treme GP, Salas C, Ortiz G, Gill GK, Johnson PJ, Menzer H, Richter DL, Qeadan F, Wascher DC, Schenck RC Jr (2019) A biomechanical comparison of the Arciero and LaPrade reconstruction for posterolateral corner knee injuries. Orthop J Sports Med. 7(4) 
114. Van Gennip S, van der Wal WA, Heesterbeek PJC, Wymenga AB, Busch VJJF (2019) Posterolateral corner reconstruction in combined injuries of the knee: improved stability with Larson's fibular sling reconstruction and comparison with LaPrade anatomical reconstruction. Knee.

115. Vezeridis PS, Engler ID, Salzler MJ, Hosseini A, Gwathmey FW Jr, Li G, Gill TJ 4th. (2019) Biomechanics following isolated posterolateral corner reconstruction comparing a fibular-based docking technique with a tibia and fibular-based anatomic technique show either technique is acceptable. Arthroscopy

116. Vicenti G, Solarino G, Carrozzo M, De Giorgi S, Moretti L, De Crescenzo A, Moretti B (2019) Major concern in the multiligament-injured knee treatment: a systematic review. Injury. 50(Suppl 2):S89-S94

117. Walker DN, Hardison RR, Schenck RC Jr (1994) A baker's dozen of knee dislocations. Am J Knee Surg. 7:117-124

118. Wascher DC, Dvirnak PC, DeCoster TA (1997) Knee dislocation: initial assessment and implications for treatment. J Orthop Trauma 11:525-529

119. Weinberg DS, Scarcella NR, Napora JK, Vallier HA (2016) Can vascular injury be appropriately assessed with physical examination after knee dislocation? Clin Orthop Relat Res 474(6):1453-1458

120. Westermann RW, Marx RG, Spindler KP, Huston LJ, MOON Knee Group, Amendola A, Andrish JT, Brophy RH, Dunn WR, Flanigan DC, Jones MH, Kaeding CC, Matava MJ, McCarty EC, Parker RD, Reinke EK, Vidal AF, Wolcott ML, Wolf BR (2019) No difference between posterolateral corner repair and reconstruction with concurrent $\mathrm{ACL}$ surgery: results from a prospective multicenter cohort. Orthop J Sports Med 7(7)

121. White CP, Cooper MJ, Bain JR, Levis CM (2012) Axon counts of potential nerve transfer donors for peroneal nerve reconstruction. Can J Plast Surg 20: 24-27

122. Woodmass JM, Romatowski NP, Esposito JG, Mohtadi NG, Longino PD (2015) A systematic review of peroneal nerve palsy and recovery following traumatic knee dislocation. Knee Surg Sports Traumatol Arthrosc 23(10): 2992-3002

123. Worley JR, Brimmo O, Nuelle CW, Cook JL, Stannard JP (2019) Incidence of concurrent peroneal nerve injury in multiligament knee injuries and outcomes after knee reconstruction. J Knee Surg 32(6):560-564

124. Xu M, Zhang Q, Dai S, Teng X, Liu Y, Ma Z (2019) Double bundle versus single bundle reconstruction in the treatment of posterior cruciate ligament injury: a prospective comparative study. Indian J Orthop 53(2):297-303

125. Zaffagnini S, lacono F, Lo Presti M, Di Martino A, Chochlidakis S, Elkin DJ, Giordano G, Marcacci M (2008) A new hinged dynamic distractor, for immediate mobilization after knee dislocations: technical note. Arch Orthop Trauma Surg 128(11)

126. Zheng L, Sabzevari S, Marshall B, Zhu J, Linde MA, Smolinski P, Fu FH (2018) Anterior cruciate ligament graft fixation first in anterior and posterior cruciate ligamento reconstruction best restores knee kinematics. Knee Surg Sports Traumatol Arthrosc 26(4):1237-1244. https://doi.org/10.1007/s00167017-4615-6 Epub 2017 Jun 23

\section{Publisher's Note}

Springer Nature remains neutral with regard to jurisdictional claims in published maps and institutional affiliations.

\section{Submit your manuscript to a SpringerOpen ${ }^{\circ}$ journal and benefit from:}

- Convenient online submission

- Rigorous peer review

- Open access: articles freely available online

- High visibility within the field

- Retaining the copyright to your article

Submit your next manuscript at $\boldsymbol{\nabla}$ springeropen.com 